\title{
Narrative Skin Repair: Bearing Witness to Representations of Self-Harm
}

\author{
Angela Failler \\ University of Winnipeg
}

\begin{abstract}
A a presentation on Marina de Van's (2002) film Dans Ma Peau (In My Skin). ${ }^{1}$ From the outset, the presenter cautioned us that the film contained graphic imagery of self-harm including the protagonist tearing at, sucking on, and eating her own, self-inflicted flesh wounds. She then proceeded to show a few clips from scenes she described as "relatively inexplicit" compared to the rest. Upon the first, three members of the already small audience sprang out of their seats and hurriedly left the room. Exactly what did these three not want to see, think about, or perhaps feel such that they were compelled to leave this way? Put differently, what did the invitation to bear witness to representations of self-harm evoke that was so unbearable? What, on the other hand, motivated the rest of us to stay? Moreover, did the feminist context matter here? And does this instance say anything
\end{abstract}

1 This presentation was given by film scholar and filmmaker Minna-Ella Altonen, doctoral candidate of the University of Glasgow at the 2oth Annual International Feminist and Women's Studies Association Conference, University of Newcastle, July 2007. Thanks to Altonen for her provocative work which inspired me to think about the significance of "turning away" from representations of self-harm.

ESC 34.1 (March 2008): 11-28 
ANgela Failler is Assistant Professor of Sociology and Women's and Gender Studies at the University of Winnipeg. Her research explores the intersection of culture, embodiment, and psychical life through conditions such as anorexia and selfharm. She is also interested in the politics of loss and memory and has published new work on remembrance practices surrounding the 1985 Air India bombings. about the status of self-harm, or representations of self-harm, in relation to popular culture?

More specifically, I recall this instance as a point of entry into a twofold discussion concerning, first, why representations of self-harm might be difficult or even unbearable to witness and, second, what the implications of this are for the potential to cultivate empathic understandings of self-harm and of those who practise self-harm. In her recent work on the politics of terror and loss in media and literature, E. Ann Kaplan (2005) argues that it is important to pay attention to representations of trauma as well as people's responses to these representations given that the majority of our encounters with trauma are, in fact, experienced vicariously through mediatized accounts rather than direct witnessing (87). Kaplan refers in her work mainly to large-scale traumatic events such as war, the Holocaust, and terrorist attacks, but her observations are also useful for thinking about encounters with self-harm since, outside of mediatized representations, selfharm is generally hidden from public view. As such, these representations not only offer rare glimpses into a rather private suffering, they operate pedagogically; that is, they operate to inform the spectator's understanding of self-harm in the absence of other kinds of encounters. Importantly, however, cultivating empathic understandings of self-harm from such occasions depends upon moving past dominant readings of self-harm that view it as a destructive behaviour with solely negative consequences to recognize instead that, for those who practise it, self-harm serves as a means of survival in the wake of psychical trauma. It is upon this recognition, I argue, that representations or mediatized accounts of self-harm can be appreciated not only for making self-harm visible but for their reparative potential. By "reparative" I do not mean that the traumatic experiences underlying self-harm are somehow undone or reversed by mediated representation or by the occasion of empathic witnessing alone but, rather, that the conditions necessary for making sense of these experiences and for articulating previously unthinkable pain might be found.

I turn to the psychoanalysis of skin for insight into what is psychically accomplished through self-harm enacted on and through the surface of the body. It is here that self-harm is understood not simply as destructive or counterproductive but as a means of protection against further emotional rupture following a devastating event, or even as a means of caring for oneself in the face of ongoing emotional turmoil. Moreover, in its attention to counter-transference-that is, in its attention to the analyst's affective responses to his or her analysands-psychoanalysis is helpful for thinking about the relationality of self-harm, including the significance of

12 | Failler 
readings and responses by others. Extrapolating from counter-transference in the psychoanalytic context to spectatorship in the context of media encounters, this paper mines both possibilities and resistances to empathic witnessing by asking how it is, exactly, that representations of self-harm get under the skin of onlookers with such force. And finally, to animate some of these ideas I introduce Winnipeg artist Hope Peterson's video Surface Damage (1992). ${ }^{2}$ While taking advantage of its symbolic potential as the body's most visible organ, Peterson represents skin as more than an impressionable surface; indeed, skin becomes a site whereupon the present and the past are brought into dynamic relation with one other in the struggle to create meaning out of a traumatic experience of violence. The aim of this paper is thus to explore the significance of mediatized representations for cultivating empathic understandings of self-harm and to insist upon the importance of reading practices in this process. In other words, I argue that bearing witness to representations of self-harm plays a crucial role in fostering their possibility as sites of what Maggie Turp calls "narrative skin repair" ("Self-Harm” 239).

\section{Limited Definitions}

"Self-harm" is typically used to refer to injuries administered directly to one's own body such as cutting, burning, pulling out hair, scratching, hitting, or bashing, and swallowing dangerous objects. Substance abuse and eating disorders are frequently included in this definition as well. Notably, injuries that result from neglect or significant lapses in self-care (rather than from self-directed actions like cutting) are often not recognized as self-harm, nor are injuries or illnesses that result from activities such as overworking, overexercising, participating in extreme sports, and smoking-all of which enjoy a level of cultural acceptability and even encouragement (Turp, "Self-Harm" 229-31). The primary basis for distinction here, between what does and does not constitute self-harm, seems to be whether or not an injury is understood to have resulted from a deliberate or intentional effort to damage the self. Injuries due to lapses in self-care or to certain culturally accepted high-risk activities are generally not understood in this way but instead are thought to be inadvertent or "accidental."

2 Special thanks to Hope Peterson who met with me to talk about Surface Damage and generously permitted the reproduction of images from the video to accompany this paper. Thanks also to Video Pool Media Arts Centre in Winnipeg for lending me Peterson's work for my research. 
In addition to underestimating the potential health risks of lapses in self-care and certain culturally accepted high-risk activities, defining selfharm strictly in terms of deliberateness or intentionality creates several limitations when it comes to recognizing and understanding motivations for self-harm and also, I argue, when it comes to reading representations of self-harm. To start, defining self-harm according to intentionality renders both the practice of self-harm and persons who self-harm largely unintelligible by inviting the question, "Who would do something like that to themselves on purpose?" In turn, this unintelligibility becomes grounds upon which to disregard self-harm or the self-harming subject as beyond sympathy or warranting interest. Such has been the reported experience of many women, for example, who present themselves in emergency rooms with serious self-inflicted injuries only to be treated by frustrated care staff as "time-wasters" or to be dismissed for "attention seeking" (Pembrooke in Kilby 128; Elmendorf 87).

Further, defining self-harm in terms of intentionality forecloses the possibility of understanding it as anything other than destructive or counterproductive since this definition takes the practice of self-harm literally; that is, by assuming that the purpose of self-harm is solely to cause damage, its significance as an attempt to articulate or work out internal suffering is missed. In other words, the unconscious motivations or conflicts that may find their expression in self-harm are overlooked by fixating on the outward spectacle of injury and the action in the most recent past that caused it. Basically, I am arguing that a view of self-harm which is preoccupied with its destructiveness-evident in the synonymous use of terms such as "deliberate self-injury," "self-inflicted violence," "self-mutilation," and "self-attack" (Kilby 126)—closes off the occasion for understanding what self-harm accomplishes psychically and, thus, why it might be endeavoured in the first place. ${ }^{3}$ It is precisely for these reasons that a turn to the psychoanalysis of skin is imperative.

\section{The Psychic Skin Boundary and Second Skins}

Esther Bick, a lesser-known but notable figure in British psychoanalytic circles, developed a set of ideas referred to as skin containment theory which has influenced psychotherapeutic understandings of self-harm. Through observing infants, Bick (1968) came to believe that our capacities for relating to and communicating with others are founded upon our

3 I have raised similar questions with respect to what is psychically accomplished in anorexia in another paper called "Appetizing Loss: Anorexia as an Experiment in Living" (2006).

14. Failler 
earliest experiences of feeling held together by a containing, skin-like object (484). Initially, the mother functions as this object, holding her infant's instinctive fear of "falling to pieces" through her touch, voice, gaze, and care of the infant's body. With consistent care, the infant eventually internalizes the mother's capacity for containment as its own and in doing so establishes a psychic skin boundary, that is, a sense of the boundary between self and (m)/other, as well as the distinction between internal and external space (Bick 84). The psychic skin boundary, then, is the correspondence of a bodily experience of containment with a mentalemotional one and is subsequently relied upon to mediate the relationship between inner and outer worlds, allowing the two to interpenetrate while maintaining a "suitable degree of ... resilience" (Turp, "Self-Harm" 235). When the psychic skin boundary is operating in relative equilibrium, an individual feels at once held together and open to exchanges with others and is able to notice and communicate internal states of being without feeling unbearably exposed. If, however, the psychic skin boundary is compromised, due either to the mother's inability to contain her infant's anxieties for reasons of her own or to some later violation of one's sense of cohesion or bodily integrity, a protective, unconscious "second skin" forms (Bick 484-86). This second skin, meant to shield the self from further harm, nevertheless has the effect of inhibiting a fluid or balanced exchange between inside and outside, ultimately inhibiting relationality and communication with others (Turp, "Self-Harm" 235). In plainer terms, because of its defensive function, the second skin makes it hard to let others in or to allow feelings out.

It is no coincidence that conflict with respect to the psychic skin boundary manifests at/on the material skin, the physical border between inside and outside. This can be seen in self-cutting, for example, where injuries result in a tangible, protective layer-a literal second skin-as scabs and scars form over the top of wounds. Although enacted corporeally and on/near the body's surface, cutting and marking the skin in this way bears deep emotional significance as both an attempt to represent psychical trauma and to compensate for it. As an attempt to represent psychical trauma, self-harm enacted upon the skin makes visible the otherwise invisible violated psychic skin boundary. It becomes, in Donna M. Elmendorf's (2007) words, "a means of concretely representing the weak and destructible boundary of the [psychic] skin" (83). In this sense, selfharm cites or repeats the earlier violation whose full impact has otherwise been rendered unconscious and inexpressible due to the stifling force of
It is no

coincidence that

\section{conflict with}

respect to the

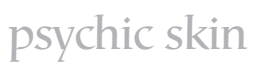

boundary

manifests at/on

the

material skin,

the physical

border between

inside and

outside. 
trauma itself (including, as is common in situations of abuse, the violator's enforcement of silence upon the one violated).

To be sure, however, the repetition enacted by self-harm is not a straightforward or literal one. It is a repetition with a crucial difference. By this I mean that unlike the original violation which compromised the psychic skin boundary and trust in the "skin-container" (Bick 484), inflicting a wound upon one's own physical skin provides an occasion to control the interpenetration of inside and outside, to re-establish a sense of boundary on one's own terms. Compulsive or repetitive cutting, for instance, tests and re-tests the skin's capacity for containment: Will it hold this time? Thus, cutting and marking the skin may be understood as an effort to define the self or the boundaries of the self, especially when one feels under threat of emotional disorganization or at risk of "falling to pieces" (Elmendorf 83). Moreover, while it may seem paradoxical, inflicting a wound upon one's own skin may create an occasion to care for the self, whether by cleaning or subsequently trying to secure the wound or merely by witnessing the wound as it appears and begins to heal. The selfinflicted flesh wound, in other words, makes an opportunity to recognize and be with one's own pain when perhaps no one else did or could. It is in this sense that self-harm not only represents psychical trauma but is an attempt to compensate for it, that is, an attempt to compensate for the traumatic loss of a resilient enough psychic skin boundary.

Self-harm, as I am proposing it here, is an effort to manage the deep pain associated with trauma locally (at the site of one's own body), topically (on/near the surface of the body), and independently (without the direct involvement of others). Notably, being involved with others risks being vulnerable, and being vulnerable may feel like risking a re-violation. With this in mind, imagine how self-inflicted flesh wounds can have the effect of keeping others at a distance, even turned away. And yet, many who have written about self-harm also describe self-harm as a language, like Janice McLane (1996) who calls it "a voice on the skin when the actual voice is forbidden" (107). To describe self-harm as a voice or a language is to suggest that despite its relative privacy self-harm may still be an attempt at articulation and, thus, a gesture toward communication. So herein lies another paradox. While self-harm as a strategy of self-containment performs a resistance to relationality, it may also be "a plea to be witnessed" (Hewitt in Kilby 124). Indeed, self-harm may be a means, however ambivalent, of seeking much-needed attention. Given these paradoxes, self-harm is also usefully thought of as hidden testimony. In hidden testimony, the original trauma or underlying psychical conflict which precipitates the 
symptom remains unconscious, unspoken, or protected (hidden), while the skin makes the pain of this trauma or conflict visible for those who bear to look.

\section{Counter-transference and Spectatorship: Bearing to Look}

To raise the significance of bearing to look is to explore what experiences and feelings arise when people encounter others who self-harm or, given the aims of this paper, when people encounter mediatized representations of self-harm. Obviously there are crucial differences between these two kinds of encounters, and yet they are worth considering alongside one another since they are both sites where the significance of interpretations/ responses can be noticed and where empathic understandings may or may not be cultivated. In fact, Kaplan (again, not speaking specifically of selfharm but of the effects of trauma nonetheless) draws a parallel between these two kinds of encounters when she argues "viewers of the media, like therapists working with trauma victims, are often vicariously traumatized" (21). Adapting Martin L. Hoffman's (200o) research on trauma and empathic witnessing in the therapeutic context, she goes on to consider if being vicariously traumatized as a media spectator blocks the potential for empathic response or if it might actually propel empathic response in the form of "responsible witnessing," that is witnessing motivated not simply by voyeuristic curiosity but by a wish to better understand the conditions out of which trauma arises and a desire to act toward changing those conditions (Kaplan 22-23).

Vicarious trauma, according to Kaplan, is experienced to greater and lesser degrees and can include everything from temporary discomfort to feeling overwhelmed, profoundly disturbed, shocked, numbed, or even having the sense of being "changed forever" by a second-hand encounter with trauma (91). Further, she suggests that while the degree to which vicarious trauma is experienced depends partly on the context of the encounter (where, when, why) and the construction of the representation in the encounter (how trauma is narrated, coded, framed), it also depends in large part on the history of experiences brought to the encounter by the spectator. Adopting Hoffman once more, Kaplan points out that the term "vicarious" is really a misnomer since it is not the pain of the other that is experienced here but, rather, the pain aroused by the intermingling of the representation of the other's trauma with one's own history of trauma and/or loss (90). In other words, in vicarious trauma, witnessing is painful or difficult because the witness's own wounds and vulnerabilities are triggered by those of the other. 
I argue that a primary reason encounters with self-harm (whether in person or mediated) get under the skin of spectators/witnesses with such force is precisely that they open us up to our own wounds and vulnerabilities and because, to borrow Judith Butler's (2004) observation, “Let's face it. We're undone by each other" (19). Echoing Kaplan's concerns about the outcomes of vicarious traumatization then, I am interested in what kinds of understandings and actions are possible when we are undone by each other in this context of shared vulnerability; namely, how can responses other than turning away from self-harm, other than defending against or disavowing this shared vulnerability, be cultivated? That is, how might we endure the triggering of our own wounds and vulnerabilities in order to recognize and contemplate the suffering of another? What could come of staying with our feelings of discomfort in the midst of the other's pain? How, this is to ask, might we bear looking at those who self-harm, and what becomes possible when we do?

Psychoanalysts and psychoanalytic psychotherapists are trained to recognize their own affective or emotional responses to their analysands and to consider these responses important resources for understanding their analysands' suffering, ultimately toward creating the best conditions for healing possible (see Heinmann 1950; Pines 1980; Turp 2003). In other words, analysts are encouraged to pay attention to how their own wounds, vulnerabilities, and desires may be triggered by their analysands' transference of particular feelings onto them in the analytic encounter, since how they subsequently negotiate this counter-transference can either hinder or assist their ability to think about the analysands' circumstances and needs. Thus the challenge for analysts is not only to be an audience for their analysands' painful feelings but, at least to some degree, to notice and stay with their own feelings as a way of being present to the intersubjective work of therapy.

In "Containment and the Use of the Skin" (2007), Donna M. Elmendorf describes the transference-counter-transference dynamic she has with her patient, "Christine." Christine violently and repeatedly damages her own skin which, on several occasions, results in hospitalization for the treatment of her wounds. Through the course of therapy, Elmendorf comes to understand Christine's self-harm as an effort to "grapple somatically" (90) with her traumatic history of sexual and physical abuse suffered at the hands of various family members during her childhood and into adulthood. Although Christine is unable to adequately express the pain of her trauma in words (a toughened second skin prevents her from doing so), Elmendorf interprets Christine's breaking through the surface of her own 
skin as an attempt both to communicate her experience as a "damaged container" (due to being repeatedly violated by others) and to signal a desire to no longer keep her pain strictly inside herself (87). She arrives at this understanding in part by paying attention to how Christine's horrifying and intolerable experiences find their response in her own feelings during their "interchanges":

Christine's experience of being "asked" to bear more than she could tolerate was repeated in her early interactions with me. I felt filled with feelings that she did not experience. Her affectively bland descriptions of her sliced skin, her perforated cheek, the smell of burned flesh, her ten-twenty-fifty sutures, all left me feeling sickened by her words and "done to" by her process. Through our interchanges, she induced in me the experience of being filled with an unnameable horror and sadness. Tacitly, she asked me to resonate with her horror... I came to see that I had to use restraint in disclosing what she stirred in me so as not to destructively re-enact the early dynamic of turning her into a receptacle for feelings that were difficult for me to contain. (88, emphasis added)

Drawing on Saul Friedlander's (1994) discussion of the difficulty of encountering traumatic representations of the Holocaust, Deborah P. Britzman (2000) captures what I see as the work Elmendorf undertakes in therapy with Christine: "Part of what must be worked through [in encountering another's trauma]," Britzman writes, "are the projective identifications that impede our capacity to make an ethical relation to the stranger, to encounter vulnerability as a relation and thus move beyond the impulse of repeating the trauma by placing helplessness and loss elsewhere" (35). What Britzman refers to here as "projective identifications," or part of what must be worked through in order to make an ethical relation to the stranger/other, is basically the difficulty of feeling "done to" by the other's suffering and the subsequent urge to either return these difficult feelings "back" to the other or to somehow cast these feelings elsewhere-as if they did not belong to us or the relationship in the first place. Sickened, horrified, and saddened in the face of Christine's wounds ("vicariously traumatized," as Kaplan might put it), Elmendorf is subsequently wary of becoming a leaky or damaged container herself in response to Christine's unspoken request to have her pain recognized and "held" by Elmendorf in therapy. That is, in order to act as a "good-enough container" for Christine's therapeutic process, Elmendorf is conscious of 


\section{To make use of}

\section{Bick's theory of}

skin

\section{containment}

\section{and second skin}

\section{formation, for}

instance, might

allow the

spectator to

look beyond the

surface of

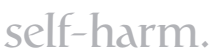

having to notice her own feelings of being "done to" and resist projecting them onto Christine so as not to re-enact the dynamics of Christine's damaging family relationships, thereby creating a trauma loop.

But what would it look like for a non-therapist-a media spectator, more specifically - to stay with his or her own feelings in this way when confronted with an image of self-harm? In other words, how can a media spectator be encouraged to bear witness to representations of self-harm, and might this encounter then translate into greater understanding of those for whom self-harm becomes a necessary means of expression? One way, I propose, is to take up the interpretive framework offered by psychoanalysis which recognizes self-harm as a symptom of trauma that accomplishes something psychically meaningful for those who practise it. To make use of Bick's theory of skin containment and second skin formation, for instance, might allow the spectator to look beyond the surface of self-harm, to see it as a compensatory effort and thus an appreciable response that-while clearly not ideal-makes sense given the devastating impact of trauma and the compromised emotional resources of the traumatized subject. The spectator, then, is in a better position to empathize with self-harm, to side with both the symptom and the self-harming subject, as it were, rather than merely feeling "done to" or helpless in the face of such suffering.

To be sure, bringing a better interpretive framework to encounters with self-harm than the dominant one (where self-harm only ever equals hopeless self-destruction) will not prevent our vulnerabilities, wounds, or projections from being triggered in the first place. Nor am I suggesting that this kind of immunity is the goal. Rather, I am suggesting that it may offer a conceptual space within which to subsequently notice and think through our own feelings as spectators/witnesses, a space through which to move beyond vicarious traumatization or the repetition of trauma toward empathic understanding and acknowledgment of the other's pain. In this spirit, I undertake a brief reading of Hope Peterson's video Surface Damage, including a few instances of the video's reception.

\section{Surface Damage: Reading a Representation of Self-harm}

Video, as a medium, has been used by artists to critique mainstream productions of moving imagery as well as conventions associated with traditional forms of art (Rush 1999). One of the ways it does this is through the self-conscious use of "imperfect" editing techniques and aesthetics which continually work to remind the viewer of the constructedness of the image and the presence of the image-creator, thus distinguishing it from

20 Failler 
productions seeking to create a seamless picture intended to convince spectators of its realism. Moreover, as artist and critic Martha Rosler (1990) notes, by engaging strategies aimed at implicating the spectator or audience in the work itself (for example, having a video-player triggered by the action of the spectator stepping into the physical space where the image is projected), video art poses a challenge to the "passivity of reception" built into more conventional modes of art and media presentation (31). It is in light of this attention to the implication of the spectator and the notion of challenging the passivity of reception that I am particularly interested in how Surface Damage, as a representation of self-harm, has gotten under people's skin.

Surface Damage is a short experimental video art work that exhibited as a single-channel installation at the Winnipeg Art Gallery in 1992. Found footage of mountaineers facing an ominous snowstorm is juxtaposed with nearly still images of skin damage and a performance of self-cutting. Through a sparse but evocative narration, the video's central metaphor takes shape: an avalanche comes to symbolize the overwhelming, traumatizing experience of domestic violence (image 1). In the first of three short monologues, the narrator recites, "Your small word or laugh brings down something so enormously out of scale, the last thought you

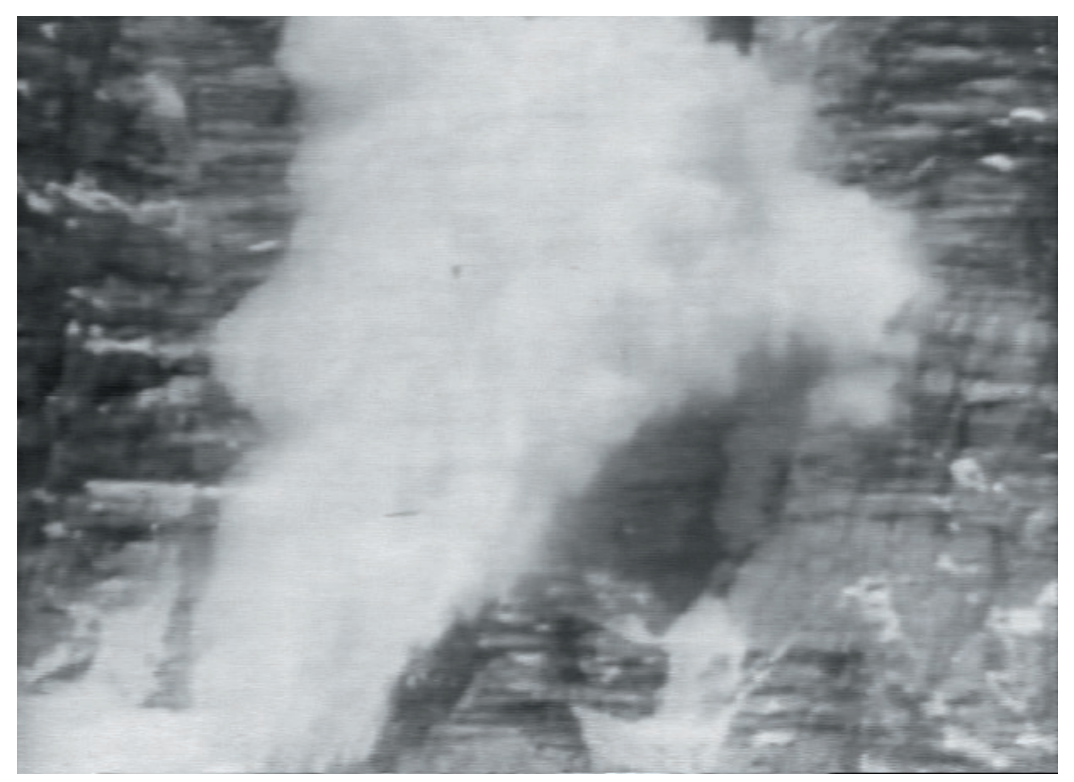

Video still from Surface Damage (1992) by Hope Peterson, reproduced by permission of the artist. 
have before the terror is one of complete shock." A scene of mountaineers struggling against a snowstorm cuts to a series of scars and skin irritations on women's bodies variously labeled "surgical," "self-inflicted," and "other" (images 2, 3, and 4), followed by a woman carving into her leg with a razor
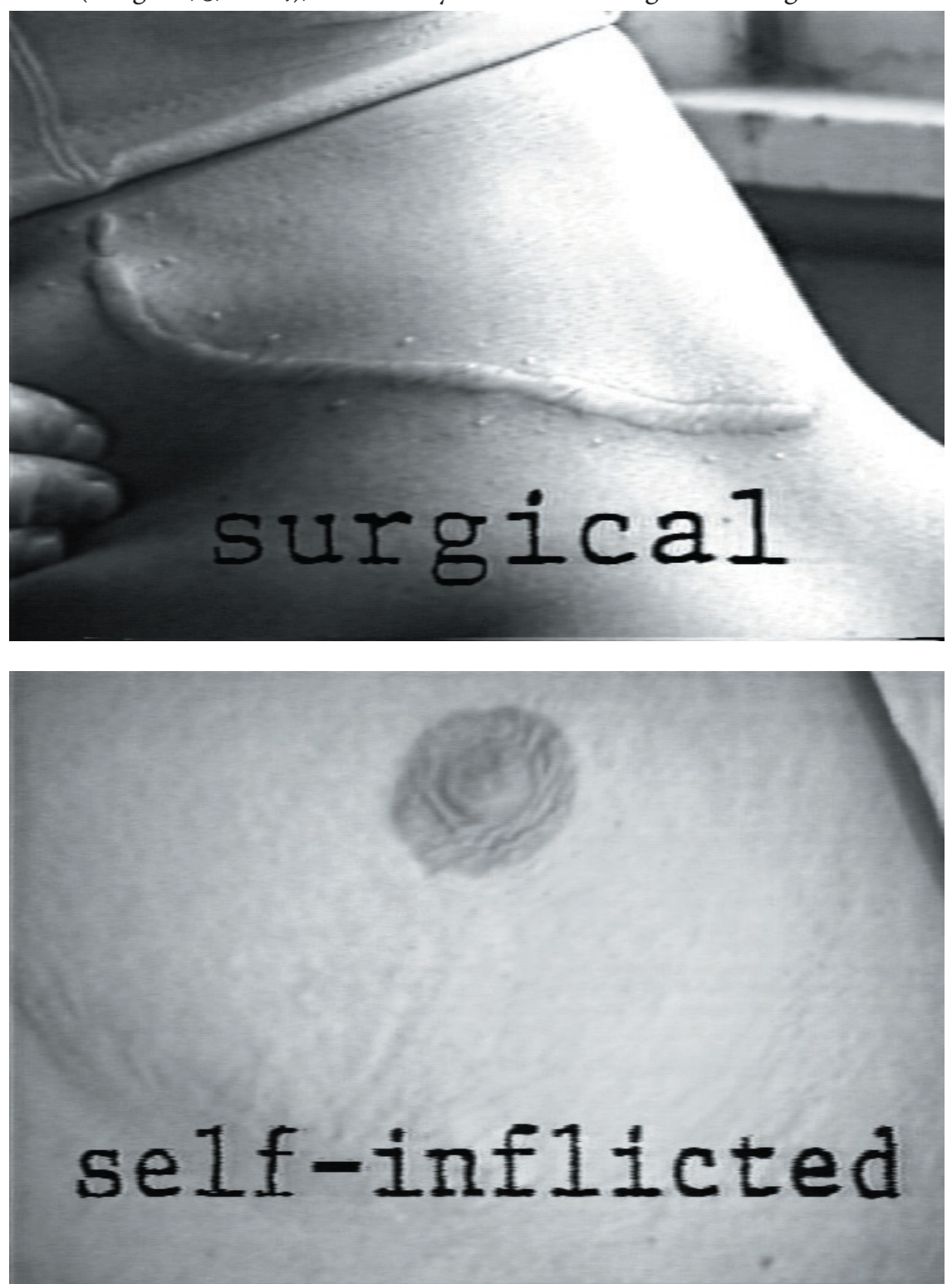

Video stills from Surface Damage (1992) by Hope Peterson, reproduced by permission of the artist. 

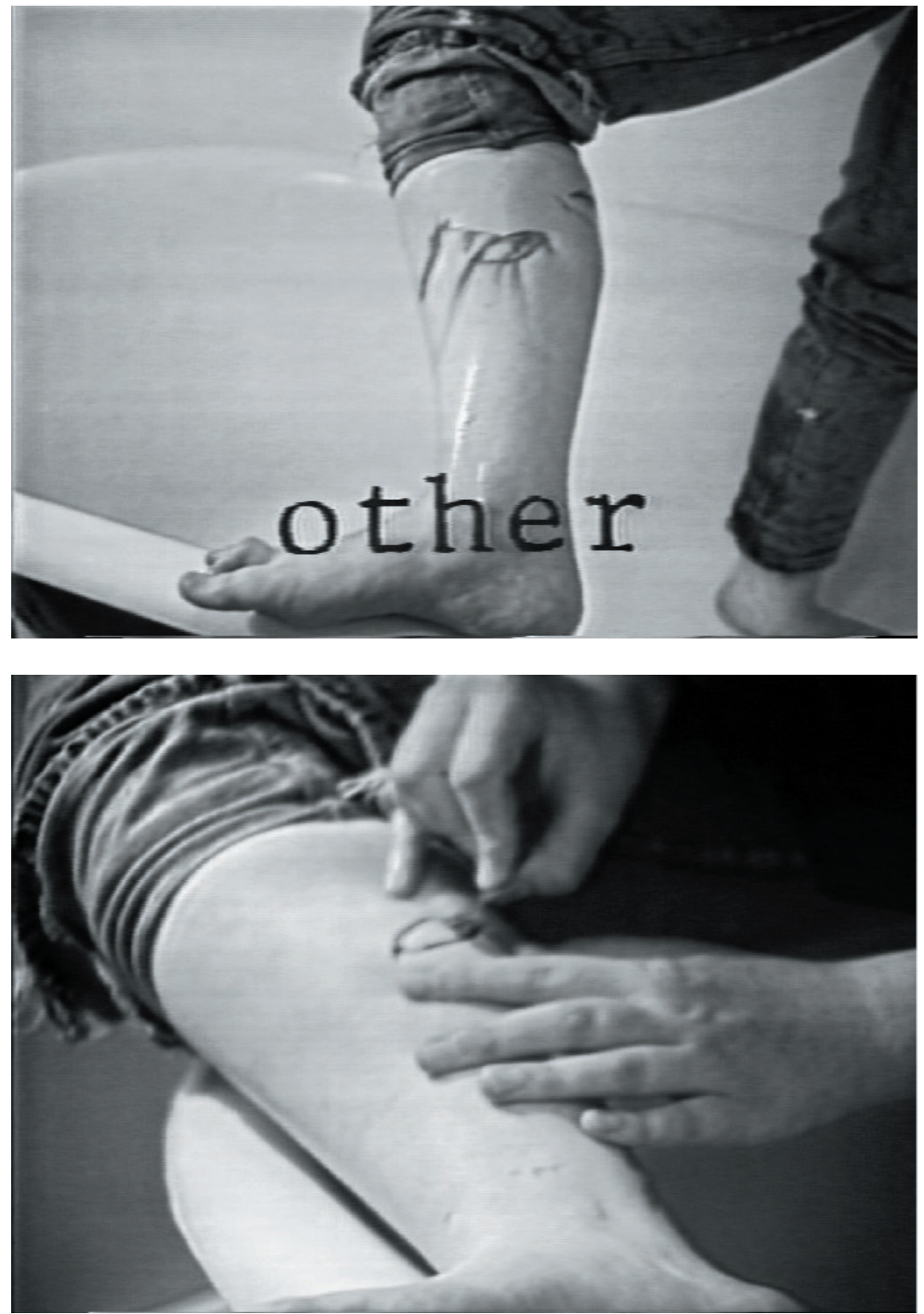

Video stills from Surface Damage (1992) by Hope Peterson, reproduced by permission of the artist. 
blade (image 5). The moving triptych of snowstorm, skin damage, and selfcutting repeats suggest that violence, especially violence that is hidden or silenced, returns by speaking through the body in various ways-namely, through its surface. This repetition communicates the traumatic repetition often concomitant with abuse.

Although Peterson has explored themes of abuse and self-harm in several of her works, reactions to Surface Damage were especially mixed and charged. Some critics lauded the tape as a reclaiming of women's bodies, rather simplistically equating self-harm with "empowerment," and subsequently failing to recognize how the artist addresses the lingering effects of trauma that self-harm and its resultant wounds would seem to make evident (see Noble 1992). Others, however, felt Surface Damage was manipulative and worried that it actually promoted violence against women. ${ }^{4}$ Interpreting the tape as manipulative, in particular, suggests that these viewers indeed felt "done to" by Peterson's work, having to defend against it rather than take up a position of empathy in relation to it. Perhaps these viewers also saw no moving beyond or outside of trauma in Surface Damage (punctuated by Peterson's use of repetition and the video's lack of narrative closure), leaving them with a sense of helplessness or powerlessness. But to understand the video itself as somehow promoting violence against women fails to recognize how the video, as an attempt at articulating the relationship of self-harm to a

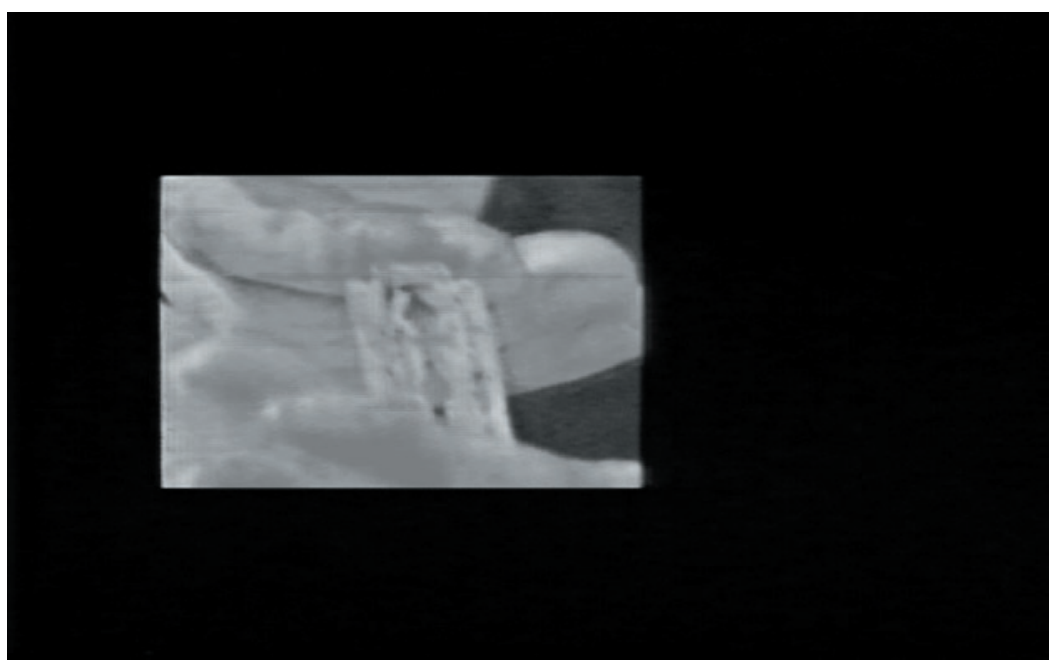

Video still from Surface Damage (1992) by Hope Peterson, reproduced by permission of the artist.

4. Personal interview with Peterson, 22 April 2008. 
specific experience of violence, is a repetition with a difference-that is, it is not simply a re-play or echo of trauma, but a means of working through it, for what Peterson has accomplished here is to transform a previously unspeakable event into a representable experience mediated through her artistic practice. ${ }^{5}$ It is precisely this transformative potential, the potential to transform silence back into the pain that was unjustly refused expression in the first place, that the narrator insists in the video's third and final monologue: "When someone says, 'Don't cry or I'll give you something to cry about,' you must continue to cry as hard as you can.... [T] he injustice of the phrase which indicates your participation in your own pain is precisely why you must continue to cry".

Undeniably, Peterson's video is difficult to watch. Her stark editing refuses any impulse toward an aestheticiation of suffering. To similar effect through the use of set inset images and lingering close-ups, her intimate framing of self-inflicted wounding refuses the spectator a safe distance from which to look (image 6). ${ }^{6}$ But most fundamentally, the work is difficult to bear witness to because Peterson invites the viewer to resonate with the horror and sadness of a traumatizing experience of violence. Thus spectators who feel manipulated or "done to" by the video are conceivably responding in the way those vicariously traumatized would. Whether this response might then be mobilized into empathic witnessing or a better understanding of those who self-harm depends, of course, upon a host of variables that can neither be generalized nor anticipated in advance-either by Peterson or viewers themselves. Nevertheless, this video art work is significant for its effort to make visible the often invis-

5 Thanks to Julia Emberley for lending me these terms to describe Peterson's work.

6 I have borrowed the phrase "aestheticization of suffering" from Lilie Chouliaraki's (2006) article by the same name. Chouliaraki analyzes BвC news footage of the bombardment of Baghdad by the American-led military coalition in March and April of 2003. She argues that the potential for empathy on the part of the spectator here was tempered by the sublime aesthetics constructed by the ввС's framing of events through various spectacular yet sanitizing production techniques including panoramic views of the sky lit up as if by fireworks. The effect, according to Chouliaraki, was to keep spectators at a safe distance from the suffering on the ground and thus less inclined to act upon or even feel an ethical obligation to real and specific suffering subjects (270). In other words, a passivity of reception was encouraged here which foreclosed opportunities for empathic witnessing. In contrast, by allowing such a close and personal view of self-harm and refusing to over-aestheticize the experience, Peterson's work invites the spectator to feel implicated in a real and specific suffering. Perhaps this implication is exactly what makes Surface Damage unbearable for some while for others it may serve as an incitement or invitation toward understanding. 


\section{narrative skin,}

in other words,

is constructed in

the relational or

intersubjective

space between

the analyst and

the analysand. ible, unspoken, interior projections of domestic violence, and for drawing attention to self-harm's "voice on the skin" as indicative of something more than "surface damage."

\section{Narrative Skin Repair: Toward a Conclusion}

Mediatized accounts of self-harm, such as Peterson's ironically titled Surface Damage, offer an opportunity to think about the important relationship between representation and witnessing in working through trauma. Psychoanalytic psychotherapist Maggie Turp believes that, in the therapeutic context, a crucial aspect of the healing process for the individual who self-harms is to gradually construct a "narrative skin" through the use of words rather than articulating or marking internal suffering by inflicting injuries upon one's own body (Hidden 206). The role of the therapist is then to receive this narration and meaningfully reflect back to the analysand his or her experiences, thereby helping build a sense of continuity previously missing on account of the shattering effects of trauma. A narrative skin, in other words, is constructed in the relational or intersubjective space between the analyst and the analysand to create a sense of enclosure within a history of experiences which helps hold the analysand together well enough to re-embark upon relations with others beyond the therapist (Turp, "Self-Harm" 238). Peterson's work, while not a narrative in the conventional (linear) sense due to its repetition and lack of closure, may nonetheless function as a kind of narrative skin in that the potential for meaning or understanding emerges similarly in the intersubjective space between the viewer and the text itself. Moreover, the potential for meaning generated here to lend significance to encounters beyond the video itself (as in, to real-life or in-person encounters with those who self-harm) depends largely upon the willingness of the spectator, like the therapist, to bear the pain of the other getting under one's skin.

In this paper I have proposed that the role of the therapist as witness in the process of narrative skin repair is useful for thinking about the potential role of the media spectator in making sense of self-harm by bearing witness to representations of self-harm. Questions around how therapists negotiate counter-transference, in particular, offer a framework for considering what the spectator brings to encounters with traumatic representations and whether or not something beyond vicarious trauma can be cultivated on these occasions. I also make this parallel by insisting that recognizing the psychic life of self-harm is crucial for cultivating empathic responses to self-harm and its expressions. That is, acknowledging self-harm's unconscious significance helps us imagine the individual

26 | Failler 
who self-harms as someone who is trying to work something out and is not simply resigned to destroying themselves and, therefore, beyond our reach or understanding. How, then, I ask, might we be less preoccupied with the spectacle of surface wounds and more attentive to the fact that the person who self-harms may be embarking upon a difficult negotiation with a history of loss or trauma through his or her self-woundings? What could it mean, in other words, to respond with interest rather than turning away or only ever feeling "done to" by the testimony self-harm offers? How can we, as onlookers, remain porous enough to absorb testimonies of self-harm and resist the urge to toughen ourselves in response? However counterintuitive it may seem, considering self-harm as a mode of selfpreservation or even as self-care allows us to appreciate it as a strategy for psychic survival, a symptom adopted to stave off something perhaps more threatening than surface damage-the prospect, in other words, of living in conscious recognition of one's traumatic past and the daunting task of re-establishing interdependence and trust. Considering self-harm in this way might allow us to understand that while second skins prevent those who self-harm from reaching directly out to others, the desire to do so still exists. As such, we might be there to receive this desire, and bearing witness to testimonies of self-harm made available to us through mediatized representations such as Peterson's is a place to start.

\section{Works Cited}

Bick, Esther. "The Experience of Skin in Early Object-Relations." International Journal of Psycho-Analysis 49 (1968): 484-86.

Britzman, Deborah P. "If the Story Cannot End: Deferred Action, Ambivalence, and Difficult Knowledge. Between Hope and Despair: Pedagogy and the Remembrance of Historical Trauma. Eds. Roger I. Simon, Sharon Rosenberg, and Claudia Eppert. Lanham: Rowman and Littlefield, 2000. 27-57.

Butler, Judith. Undoing Gender. New York, London: Routledge, 2004.

Chouliaraki, Lilie. "The Aestheticization of Suffering on Television." Visual Communication 5.3 (2006): 261-85.

Dans Ma Peau. Dir. Marina de Van. Perf. Marina de Van. 2002. DvD. Wellspring Media, 2004.

Elmendorf, Donna M. "Containment and the Use of Skin." The Embodied Subject: Minding the Body in Psychoanalysis. Eds. John P. Muller and Jane G. Tillman. Lanham: Jason Aronson, 2007. 81-82. 
Failler, Angela. "Appetizing Loss: Anorexia as an Experiment in Living." Eating Disorders 14 (2006): 99-107.

Frielander, Saul. “Trauma, Memory, and Transference." Holocaust Remembrance: The Shapes of Memory. Ed. Geoffrey H. Hartman. Oxford: Blackwell, 1994. 252-63.

Gillmor, Alison. "Humour Eases Pain of Brutal Exhibit." Winnipeg Free Press. 13 March 1993: B8.

Heimann, Paula. “On Counter-transference." International Journal of Psychoanalysis 31 (1950): 81-85.

Hoffman, Martin L. Empathy and Moral Development: Implications for Caring and Justice. New York: Cambridge UP, 2000.

Kaplan, E. Ann. Trauma Culture: The Politics of Terror and Loss in Media and Literature. New Brunswick: Rutgers UP, 2005.

Kilby, Jane. "Carved in Skin: Bearing Witness to Self Harm.” Thinking Through the Skin. Eds. Sara Ahmed and Jackie Stacey. London, New York: Routledge, 2001. 124-42.

McLane, Janice. "The Voice on the Skin: Self-Mutilation and MerleauPonty's Theory of Language." Hypatia 11.4 (1996): 107-18.

Noble, Richard. "Susan Peterson." Catalogue essay for the Manitoba Studio Series of the Winnipeg Art Gallery, 1992.

Pines, Dinora. "Skin Communication: Early Skin Disorders and Their Effect on Transference and Countertransference." International Journal of Psycho-Analysis 61 (1980): 315-24.

Rosler, Martha. "Video: Shedding the Utopian Moment." Illuminating Video: An Essential Guide to Video Art. Eds. Doug Hall and Sally Jo Fifer. New York: Aperture Foundation, 1990. 31-50.

Rush, Michael. New Media in Late $20^{\text {th }}$ Century Art. London: Thames and Hudson, 1999.

Surface Damage. Directed by Hope Susan Peterson. 3/4" SP 14:0o (colour, mono). DVD. Video Pool, 1992.

Turp, Maggie D. "Self-Harm by Omission: A Question of Skin Containment." Psychodynamic Practice 13.3 (2007): 229-44.

- Hidden Self-Harm: Narratives from Psychotherapy. London: Jessica Kingsley, 2003. 